\title{
ESTIMASI POTENSI BIOGAS DARI PALM OIL MILL EFFLUENT (POME) PABRIK KELAPA SAWIT DI PROVINSI JAMBI
}

\author{
Guntar Marolop S dan Hadrah \\ Program Studi Teknik Lingkungan, Fakultas Teknik \\ Universitas Batanghari \\ hadrah.hasan@gmail.com, saragih.guntarmarolop@gmail.com
}

\begin{abstract}
The increasing of palm oil mills as a result of an increase in public interest of land exploitation to produce palm oil can cause high environmental pollution if the waste oil generated were not managed properly. Palm Oil Mill Effluent (POME) is the wastewater generated by palm oil extraction process. On the other hand, POME is a renewable energy source. To address the need for electrical energy increases, the monitoring of POME is an effort that needs to be studied because POME is no longer a pollutant to the environment but a helpful resource. This study uses field data collection in the form of POME volume and treatment plant process management to determine the COD levels so that the estimation of total biogas can be done. Based on the calculation of the energy potential of POME in Jambi province with processing capacity of the entire Province amounted to 1,230 tons FFB / hour, 20 hours operating time / day and COD content of 50,000 $\mathrm{mg} / \mathrm{L}$, the amount of energy can be obtained is $737.712 \mathrm{MWh} /$ day or $269.26 \mathrm{GWh} / \mathrm{Year}$.
\end{abstract}

Keywords: POME, biogas, energy

\section{PENDAHULUAN}

Perkembangan penggunaan lahan di Provinsi Jambi untuk perkebunan dan pertanian sejak tahun 1990 hingga tahun 2012 (Gambar 1) menunjukkan pengusahaan lahan sawit di Provinsi Jambi yang selalu meningkat. Potensi produksi minyak sawit di Provinsi Jambi sebagai salah satu wilayah dengan luas lahan sawit terbesar di Indonesia tentunya diiringi dengan produksi limbah cair yang tinggi pula.

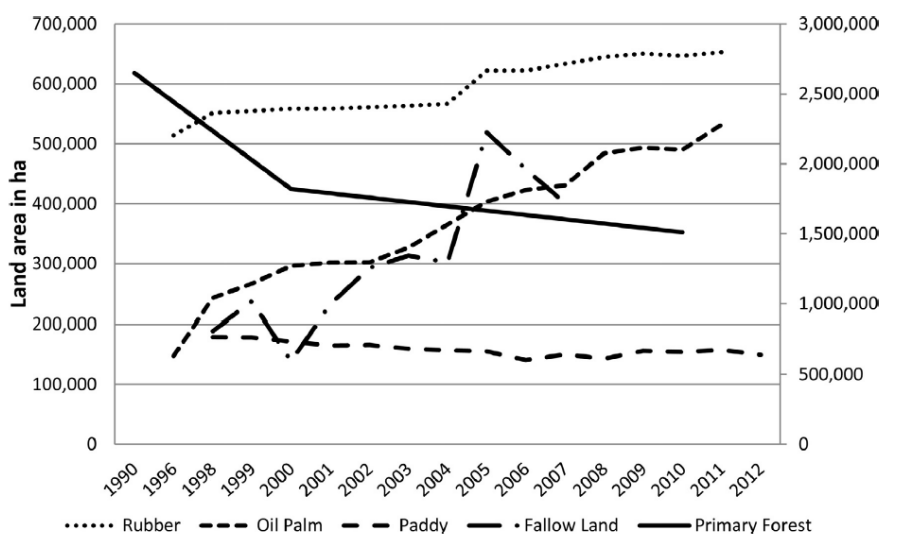

Gambar 1. Grafik Perubahan Penggunaan Lahan di Provinsi jambi Tahun 19902012 (Aksis vertikal kiri menunjukkan luas lahan perkebunan karet, sawit dan padi sedangkan aksis vertikal kanan menunjukkan luas hutan primer)

Salah satu metode pengolahan limbah yang baik adalah dengan memanfaatkan limbah biomassa untuk menghasilkan sumber energi (biofuel) seperti biogas atau biochar. Proses produksi minyak sawit pada Pabrik Kelapa 
Sawit (PKS) dapat menghasilkan limbah berupa fase padat dan cair. Palm Oil Mill Effluent (POME) merupakan limbah cair kelapa sawit yang dihasilkan dalam proses ekstraksi minyak sawit meliputi sterilisasi Tandan Buah Segar (TBS), penjernihan minyak sawit mentah atau Crude Palm Oil (CPO) dan pemerasan tandan kosong.

Pengolahan POME menjadi biogas tentu dapat mencegah terjadinya pencemaran lingkungan. Selain itu, tingginya produksi POME sebagai dampak banyaknya jumlah pabrik kelapa sawit di provinsi $\mathrm{Jambi}^{3}$ dapat digunakan untuk memenuhi kebutuhan energi di wilayah setempat ataupun menjadi salah satu potensi ekonomi unggulan daerah dengan menghasilkan energi terbarukan. Oleh karena itu, perlu dilakukan studi estimasi perhitungan potensi biogas dari POME yang dihasilkan Pabrik Kelapa Sawit di Provinsi Jambi.

\section{METODOLOGI PENELITIAN}

Teknologi pengolahan limbah cair (Palm Oil Mill Effluent - POME) telah banyak digunakan untuk mengambil biogas dari POME seperti Bio Reaktor dan Covered Lagoon atau sistem capped anaerobic pond, dengan menutup kolam limbah konvensional dengan bahan reinforced polypropylene sehingga berfungsi sebagai anaerobic digester (Safrizal, 2015).

Berbagai metode pengolahan POME dapat dilakukan untuk menurunkan kadar polutan sehingga tidak mencemari lingkungan. Namun potensi POME sebagai bahan penghasil biogas hanya diperoleh dengan menggunakan pengolahan secara anaerob.

\section{Perbandingan Penguraian Anaerobik dan Aerobik}

Baik penguraian anaerobik maupun aerobic secara efektif dapat mendegradasi zat organik. Proses anaerobik terjadi dalam kondisi tanpa oksigen, sedangkan proses aerobik berlangsung apabila terdapat oksigen.

Alasan utama memilih proses anaerobik adalah kemampuannya dalam menghasilkan biogas dengan baik. Proses aerobik tidak mengkonversi zat organik menjadi metana, menghasilkan lebih banyak lumpur dan mengolah limbah lebih tuntas. Sebaliknya, proses anaerobik menghasilkan metana dan sisa limbah cair yang kaya nutrisi seperti nitrogen dan fosfor. Pemilik perkebunan kelapa sawit dapat menggunakan sisa limbah cair ini untuk pemupukan (Ade Sri Rahayu dkk., 2015).

Mekanisme reaksi pada fermentasi POME secara anaerob yaitu :

1. Proses Hidrolisis :

$\mathrm{C}_{6} \mathrm{H}_{12} \mathrm{O}_{6} \longrightarrow 2 \mathrm{CH}_{3} \mathrm{CH}_{2} \mathrm{COOH}+\mathrm{O}_{2}$

$\mathrm{C}_{6} \mathrm{H}_{12} \mathrm{O}_{6} \longrightarrow \mathrm{CH}_{3} \mathrm{CH}_{2} \mathrm{CH}_{2} \mathrm{COOH}+\mathrm{CH} 3 \mathrm{COOOH}+\mathrm{O}_{2}$

2. Proses Asidogenesis
$2 \mathrm{CH}_{3} \mathrm{CH} 2 \mathrm{CH} 2 \mathrm{COOH}+\mathrm{SO}^{2} \longrightarrow$
$4 \mathrm{CH} 3 \mathrm{COOH}+\mathrm{H}_{2} \mathrm{~S}$
$\mathrm{CH}_{3} \mathrm{CH}_{2} \mathrm{COOH}+3 \mathrm{H}_{2} \mathrm{O} \longrightarrow$
$\mathrm{CH} 3 \mathrm{COOH}+\mathrm{HCO}^{-}+2 \mathrm{H}^{+}+6 \mathrm{H}_{2}$
$\mathrm{CH}_{3} \mathrm{CH}_{2} \mathrm{CH}_{2} \mathrm{COOH}+2 \mathrm{H}_{2} \mathrm{O} \longrightarrow$
$2 \mathrm{CH}_{3} \mathrm{COOH}+4 \mathrm{H}^{+}$

3. Proses Metanogenesis
$\mathrm{HC}) 3-+4 \mathrm{H} 2+2 \mathrm{H} \longrightarrow$
$\mathrm{CH}_{3} \mathrm{COOH}$
$2 \mathrm{CH}_{4}+6 \mathrm{H}_{2} \mathrm{O}$
$\mathrm{CH}_{4}+\mathrm{CO}_{2}$

\section{Perhitungan Produksi Biogas}

Dalam penelitian ini dilakukan studi literatur, pengumpulan dan pengolahan data, perhitungan total produksi POME dari PKS di Provinsi Jambi serta 
perhitungan total produksi biogas $\mathrm{CH}_{4}$ (Metana) yang dihasilkan untuk dapat digunakan sebagai sumber energi.

Penelitian ini menggunakan metode pengumpulan data lapangan berupa volume inlet PKS, proses pengelolaan instalasi pengolahan air limbah untuk mengetahui kadar COD sehingga estimasi jumlah produksi biogas dapat dilakukan.

Perhitungan produksi biogas dari POME dilakukan dengan menggunakan asumsi berdasarkan data statistik rata-rata produksi biogas dari POME di sejumlah PKS oleh USAID (2015).

Tabel 1. Menghitung Potensi Energi Terbarukan dari POME

\begin{tabular}{|c|c|c|}
\hline Parameter & Unit & Keterangan \\
\hline Jam Operasi & Jam/hari & $\begin{array}{l}\text { Rata-rata jumlah jam operasi } \\
\text { pabrik dalam sehari }\end{array}$ \\
\hline Hari Operasi & Hari/tahun & $\begin{array}{l}\text { Rata-rata jumlah hari pabrik } \\
\text { beroperasi dalam setahun }\end{array}$ \\
\hline TBS Tahunan & Ton TBS/tahun & $\begin{array}{l}\text { Jumlah TBS yang diproses } \\
\text { dalam setahun }\end{array}$ \\
\hline Rasio POME terhadap TBS & $\mathrm{M}^{3} /$ ton TBS & $\begin{array}{l}\text { Rasio Volume POME yang } \\
\text { dihasilkan per TBS yang } \\
\text { diolah POME }: \text { TBS }=\left(\mathrm{m}^{3}\right. \\
\text { POME }) /(\text { ton TBS })\end{array}$ \\
\hline COD & $\mathrm{Mg} / \mathrm{l}$ & $\begin{array}{l}\text { COD limbah cair yang } \\
\text { dianalisis dengan } \\
\text { spektrofotometer }\end{array}$ \\
\hline
\end{tabular}

Sumber: Buku Panduan Konversi POME Menjadi Biogas, Sri Rahayu, Ade. dkk. (2015)

Perhitungan ini didasarkan asumsi parameter operasi. Tabel berikut merinci asumsi tersebut.

Tabel 2. Asumsi dalam Menghitung Potensi Daya

\begin{tabular}{ccccl}
\hline Parameter & Simbol & Nilai & Satuan & \multicolumn{1}{c}{ Keterangan } \\
\hline $\begin{array}{c}\text { Rasio } \\
\text { konversi } \mathrm{CH}_{4} \\
\text { terhadap } \\
\text { COD }\end{array}$ & $\mathrm{CH}_{4} / \mathrm{COD}$ & 0,35 & $\begin{array}{c}\mathrm{Nm}^{3} \mathrm{CH}_{4} / \mathrm{kg} \\
\mathrm{COD} \\
\text { removed }\end{array}$ & $\begin{array}{l}\text { Volume metana yang dihasilkan per } \\
\text { kg COD yang dihilangkan dari air } \\
\text { limbah secara teoritis }\end{array}$ \\
$\begin{array}{c}\text { Efisiensi } \\
\text { COD }\end{array}$ & $\mathrm{COD}_{\text {eff }}$ & $80-95$ & $\%$ & $\begin{array}{l}\text { Persentase COD yang akan diubah } \\
\text { menjadi metana }\end{array}$ \\
$\begin{array}{c}\text { removal } \\
\text { Nilai energi } \\
\text { metana }\end{array}$ & $\mathrm{CH}_{4, \text { ev }}$ & 35,7 & $\mathrm{MJ} / \mathrm{m}^{3}$ & $\begin{array}{l}\text { Kandungan energi metana } \\
\begin{array}{c}\text { Rata-rata } \\
\text { efisiensi } \\
\text { kelistrikan }\end{array}\end{array}$ \\
$\mathrm{Gen}_{\mathrm{eff}}$ & $38-42$ & $\%$ & $\begin{array}{l}\text { Efisiensi gas engine dalam } \\
\text { mengkonversi nilai energi metana } \\
\text { menjadi energi listrik }\end{array}$ \\
\hline
\end{tabular}

Sumber : Buku Panduan Konversi POME Menjadi Biogas, Sri Rahayu, Ade. dkk. (2015)

Berdasarkan asumsi-asumsi yang tercantum pada Tabel 1 dan Tabel 2 maka dapat dilakukan perhitungan potensi daya dengan tahapan sebagai berikut :

1. Bahan baku harian (ton TBS/hari) $=\frac{\text { TBS olah Tahunan }}{\text { Hari operasi dalam setahun }}$

2. Aliran limbah cair harian $\left(\mathrm{m}^{3} / \mathrm{hari}\right)=$ volumelimbah cair harian $x$ rasio POME terhadap TBS 


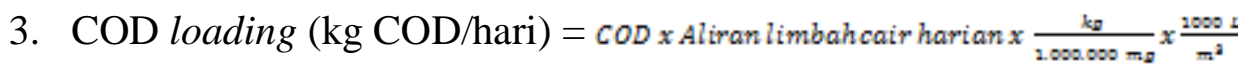

4. Produksi $\mathrm{CH}_{4}\left(\mathrm{Nm}^{3} \mathrm{CH}_{4} /\right.$ hari $)=\operatorname{COD}$ loading $x \mathrm{COD}_{\text {eff }} x \mathrm{CH}_{4} / C O D$

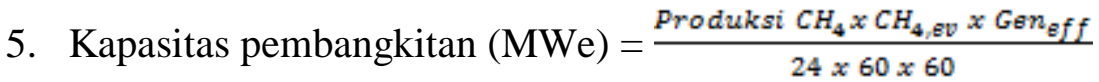

\section{HASIL DAN PEMBAHASAN}

Jumlah Tandan Buah Segar yang diolah di Pabrik Kelapa Sawit

Pabrik Kelapa sawit dirancang bekerja selama 24 jam sehari, namun karena adanya perawatan mesin PKS dan lain-lian, sangat mustahil mengoperasikan PKS selama 24 Jam sehari. Dari beberapa informasi yang diperoleh dari Manajemen PKS, menyebutkan bahwa suatu PKS dioperasikan hanya maksimal 20 jam sehari.

Perkiraan TBS yang dihasilkan di Provinsi Jambi sesungguhnya lebih dari 10.000.000 ton per tahun. Namun TBS tersebut ada yang diolah di luar Provinsi Jambi, yang dijual oleh pemiliknya ke Provinsi Sumatera Selatan, Riau, dan Provinsi Sumatera Barat. Perkiraan TBS yang diolah di PKS di Provinsi Jambi adalah seperti pada Tabel di bawah.

Tabel 3 Data Pabrik Kelapa Sawit (PKS) di Provinsi Jambi

\begin{tabular}{|c|c|c|c|c|}
\hline No & $\begin{array}{c}\text { Nama } \\
\text { Perusahaan }\end{array}$ & $\begin{array}{l}\text { Kapasitas } \\
\text { (ton/jam) }\end{array}$ & $\begin{array}{l}\text { Lokasi } \\
\text { (Desa) }\end{array}$ & Kabupaten \\
\hline 1 & PTP VI Pinang Tinggi & 60 & Sungai Bahar Tengah & $\begin{array}{l}\text { Muara } \\
\text { Jambi }\end{array}$ \\
\hline 2 & PTP VI Tanjung Lebar & 60 & $\begin{array}{l}\text { Sungai Bahar } \\
\text { Selatan }\end{array}$ & sda \\
\hline 3 & PTP VI Bunut & 60 & Sungai Bahar Utara & sda \\
\hline 4 & PT Angso Dou Sawit & 60 & Mestong & sda \\
\hline 5 & PT Brahma Bina Bakti & 30 & Desa Brahma & sda \\
\hline 6 & PT Sumbertama Nusa Pertiwi & 60 & Kec Kumpe Ulu & sda \\
\hline 7 & PT Era Forestama & 60 & Kec Kumpe Ulu & sda \\
\hline 8 & PT Bahari Gembira Ria & 30 & Kec Muara Sebo & sda \\
\hline 9 & PT Petaling Mandra Guna & 30 & Kec. Muara Sebo & sda \\
\hline 10 & PT Makin Group & 60 & Kec Kumpe Ilir & sda \\
\hline 11 & $\begin{array}{l}\text { PT Bukit Barisan Indah Prima } \\
\text { (BBIP) }\end{array}$ & 45 & Sungai Toman & $\begin{array}{c}\text { Tanjung } \\
\text { Jabung } \\
\text { Timur }\end{array}$ \\
\hline 12 & PT Kedaton & 45 & Muara Jangga & Batang Hari \\
\hline 13 & PTP VI Durian Luncup & 60 & Durian Luncup & sda \\
\hline 14 & PT Indo Sawit Subur & 30 & Muara Sebo Ilir & sda \\
\hline 15 & PT Delimuda Perkasa & 30 & Mersam & sda \\
\hline 16 & PT Asiatik Persada & 60 & Bungku & sda \\
\hline 17 & PT Humusindo & 30 & Muara Tembesi & sda \\
\hline 18 & PT Pratama Agro Sawit & 30 & $\begin{array}{l}\text { Kec. Muara Bulian } \\
\text { dan Muara Sebo Ilir }\end{array}$ & sda \\
\hline 19 & PT Palma Abadi & 30 & Kec. Muara Papalik & $\begin{array}{c}\text { Tanjung } \\
\text { Jabung } \\
\text { Barat }\end{array}$ \\
\hline 20 & PT Mitra Sawit Jambi & 45 & Kec. Muara Papalik & sda \\
\hline 21 & PT Agro Mitra Madani & 30 & Tebing Tinggi & sda \\
\hline 22 & PT Agung Agrolaksana & 45 & Kec. Muara Papalik & sda \\
\hline 23 & PT Inti Indo Sawit Subur & 45 & Tungkal Ulu & sda \\
\hline
\end{tabular}




\begin{tabular}{|c|c|c|c|c|}
\hline No & $\begin{array}{c}\text { Nama } \\
\text { Perusahaan }\end{array}$ & $\begin{array}{c}\text { Kapasitas } \\
\text { (ton/jam) }\end{array}$ & $\begin{array}{l}\text { Lokasi } \\
\text { (Desa) }\end{array}$ & Kabupaten \\
\hline 24 & PT Emal & 30 & $\begin{array}{c}\text { Lubuk Kepayang } \\
\text { Kec. Air Hitam }\end{array}$ & Sarolangun \\
\hline 25 & PT Kresna Duta Agroindo & 45 & $\begin{array}{c}\text { Pelakar } \\
\text { Kec. Bathin VIII }\end{array}$ & sda \\
\hline \multirow[t]{4}{*}{26} & PT Rigunas Agri Utama & 60 & Kec. Tebo Ilir & Muara Tebo \\
\hline & $\begin{array}{l}\text { Kapasitas PKS } \\
\text { (ton TBS/jam) }\end{array}$ & 1.230 & & \\
\hline & $\begin{array}{l}\text { Jumlah TBS per Hari } \\
(1 \text { hari }=20 \text { jam })\end{array}$ & $\begin{array}{l}24.600 \\
\text { (ton/hari) }\end{array}$ & & \\
\hline & $\begin{array}{l}\text { Jumlah TBS per Tahun } \\
\text { (1 tahun = } 365 \text { hari })\end{array}$ & $\begin{array}{l}8.976 .000 \\
\text { (ton/thn) }\end{array}$ & & \\
\hline
\end{tabular}

Sumber : Dinas Lingkungan Hidup Kabupaten se-Provinsi Jambi, 2016

\section{Perkiraan Jumlah Limbah Padat PKS}

Limbah padat PKS juga dimanfaatkan oleh pemilik PKS untuk bahan baku pembakaran boiler. Limbah yang banyak dimanfaatkan adalah serabut dan tandan kosong, sementara cangkang sawit dijual ke pihak yang membutuhkan.

Dalam Disbun Prov. Jambi, 2012 disebutkan bahwa TBS yang diolah di PKS akan menghasilkan CPO sebanyak 20\%, PKO 4\%, serabut sebanyak 13\%, tandan kosong $23 \%$ dan cangkang sawit 6,5\% serta limbah pelepah 12,6\%. Dengan demikian, perkiraan jumlah masing-masing limbah padat sisa olahan dari 26 PKS tersebut adalah seperti pada tabel di bawah.

Tabel 4 Perkiraan Jumlah Limbah Padat TBS Sisa Olahan PKS

\begin{tabular}{ccccccc}
\hline Tahun & $\begin{array}{c}\text { Jumlah } \\
\text { TBS } \\
\text { (ton) }\end{array}$ & $\begin{array}{c}\text { Tandan } \\
\text { kosong } \\
\text { (ton) }\end{array}$ & $\begin{array}{c}\text { Serabut } \\
\text { (ton) }\end{array}$ & $\begin{array}{c}\text { Pelepah } \\
\text { (ton) }\end{array}$ & $\begin{array}{c}\text { Cangkang } \\
\text { Sawit } \\
\text { (ton) }\end{array}$ & $\begin{array}{c}\text { Jumlah } \\
\text { Semua } \\
\text { Limbah } \\
\text { (ton) }\end{array}$ \\
\hline & & $23 \%$ & $13 \%$ & $12,6 \%$ & $6,5 \%$ & $(55,1 \%)$ \\
2016 & 8.976 .000 & 2.064 .480 & 1.166 .880 & 1.130 .876 & 583.440 & 4.945 .776 \\
\hline
\end{tabular}

Sumber : Data olahan, 2017

\section{Perkiraan Jumlah Limbah Cair PKS}

Limbah yang menjadi perhatian di PKS adalah limbah cair atau yang lebih dikenal dengan POME (Palm Oil Mill Effluent). POME ialah air buangan yang dihasilkan oleh pabrik kelapa sawit utamanya berasal kondensat rebusan, air hidrosiklon, dan sludge separator.

Setiap satu (1) ton TBS yang diolah akan terbentuk sekitar 0,6 hingga $1 \mathrm{~m}^{3}$ POME. POME kaya akan karbon organik dengan nilai COD lebih $40 \mathrm{~g} / \mathrm{L}$ dan kandungan nitrogen sekitar 0,2 dan $0,5 \mathrm{~g} / \mathrm{L}$ sebagai nitrogen ammonia dan total nitrogen. Sumber POME berasal dari unit pengolahan yang berbeda, terdiri dari :

a. $60 \%$ dari total POME berasal dari stasiun klarifikasi;

b. $36 \%$ dari total POME berasal dari stasiun rebusan;

c. $4 \%$ dari total POME berasal stasiun inti.

Perkiraan jumlah POME per tahun (1 ton TBS $=0,6 \mathrm{~m}^{3}$ POME) sisa olahan dari 26 PKS tersebut adalah seperti pada tabel di bawah. 
Tabel 5 Perkiraan jumlah limbah POME TBS sisa olahan PKS

\begin{tabular}{ccc}
\hline Tahun & Jumlah TBS (ton) & $\begin{array}{c}\text { Volume POME }\left(\mathbf{m}^{\mathbf{3}}\right) \\
\left(1 \text { ton TBS }=0,6 \mathrm{~m}^{3} \text { POME }\right)\end{array}$ \\
\hline 2016 & 8.976 .000 & $5.385,600$ \\
\hline \multicolumn{2}{c}{ Sumber : Data olahan, 2017} &
\end{tabular}

\section{Estimasi Produksi Energi dari POME}

Berdasarkan asumsi produksi $\mathrm{CH} 4$ yang dihasilkan menurut data statistik rata-rata seperti diuraikan pada Tabel 3.2 maka dapat dihitung produksi metan dari limbah cair (POME) PKS di Provinsi Jambi seperti berikut:

1. Bahan baku harian $=\frac{8.976 .000 \mathrm{TonTBS} / \mathrm{Tahun}}{365 \mathrm{hari} / \mathrm{Tahun}}=24.600 \mathrm{Ton} \mathrm{TBS} / \mathrm{hari}$

2. Aliran limbah cair harian $=24.600 \times 0,6=14.760 \mathrm{~m}^{3} /$ hari

3. COD loading $=$

$$
40.000 \frac{\mathrm{mg}}{\mathrm{L}} \times 14.760 \frac{\mathrm{m}^{\mathrm{s}}}{\text { hari }} \times \frac{\mathrm{kg}}{1.000 .000 \mathrm{mg}} \times \frac{1000 \mathrm{~L}}{\mathrm{~m}^{\mathrm{g}}}=590.400 \mathrm{~kg} \text { COD } / \text { hari }
$$

4. Produksi $\mathrm{CH}_{4}=590.400 \frac{\mathrm{kg} \mathrm{COD}}{\text { hari }} \times 90 \% \times 0,35 \frac{\mathrm{Nm}^{\mathrm{s}} \mathrm{CH}_{4}}{\mathrm{kgCOD}}=185.976 \frac{\mathrm{Nm}^{\mathrm{g}} \mathrm{CH}_{4}}{\text { hari }}$

5. Kapasitas Pembangkitan $=\frac{185.976 \mathrm{Nm}^{\mathrm{s}} \times 35,7 \frac{\mathrm{MJ}}{\mathrm{m}^{\mathrm{s}}} \times 0,4}{24 x 60 \times 60}=30,738 \mathrm{MWe}$

Ketersediaan sumber energi terbarukan di Provinsi Jambi sangat dibutuhkan mengingat peningkatan jumlah pemakaian energi yang selalu terjadi. Secara lebih spesifik, berdasarkan penelitian yang dilakukan oleh Joni Martin dkk (2016) dapat diketahui penggunaan energi di Provinsi Jambi berdasarkan sektor pemakaian yaitu sektor rumah dengan kebutuhan energi listrik yakni 691 GWh/Tahun, sektor usaha besar dan kecil dengan kebutuhan energi listrik 222 $\mathrm{GWh}$ /Tahun dan sektor industri sebesar $101 \mathrm{GWh} /$ Tahun sedangkan penggunaan terkecil oleh sektor publik meliputi Perkantoran pemerintah dan sekolah yaitu 75 GWh/Tahun.

Kebutuhan energi listrik Provinsi Jambi dipasok dari 2 wilayah, yakni wilayah Jambi dan sebagian dari wilayah Sumatera Barat. Namun secara umum, sumber pasokan energi listrik untuk Provinsi Jambi berasal dari tenaga diesel (PLTD) sebesar 19,85 GWh. Untuk memenuhi kekurangan pasokan energi yang berasal dari diesel, pasokan energi juga di penuhi dari Tenaga Gas (PLTG) sebesar 61,77 MW, dan tenaga mesin gas (202 MW).

Berdasarkan perhitungan potensi energi yang dihasilkan dari POME PKS di Provinsi Jambi sepeti telah diuraikan sebelumnya, dapat diketahui bahwa total energi yang dihasilkan adalah 30,738 MWe atau 737,712 MWh/hari atau setara 269,26 GWh/Tahun sehingga jika digunakan sebagai salah satu sumber energi di Provinsi Jambi, jumlah tersebut dapat memenuhi $24,7 \%$ dari total penggunaan energi listrik di Provinsi Jambi pada Tahun 2016. Jika dikaji berdasarkan sektor pengguna, jumlah energi yang dihasilkan dari POME PKS Provinsi Jambi juga dapat digunakan untuk memenuhi penggunaan energi listrik pada sektor industri (101 GWh) dan sektor publik (75 GWh).

\section{KESIMPULAN}

Analisis mengenai estimasi potensi biogas dari bahan baku POME pada PKS di seluruh Provinsi Jambi memberikan gambaran kepada penulis sehingga 
dapat disimpulkan bahwa berdasarkan perhitungan potensi energi POME PKS di Provinsi Jambi dengan kapasitas olahan dari seluruh PKS sebesar 1.230 ton TBS/Jam dengan waktu operasi 20 jam/hari dan kandungan COD sebesar 50.000 $\mathrm{mg} / \mathrm{L}$ dapat diperoleh energi sejumlah 737,712 $\mathrm{MWh} / \mathrm{hari}$ atau 269,26 GWh/Tahun.

Berdasarkan penelitian mengenai potensi energi terbarukan dari limbah POME PKS di Provinsi Jambi, diketahui bahwa PKS di Provinsi Jambi sangat mampu menunjang energi di Provinsi Jambi jika penanganan limbah POME dilakukan secara terpadu sehingga diharapkan pada masa yang akan datang potensi ini dimanfaatkan oleh Pemerintah maupun pihak swasta agar membantu ketersediaan energi di wilayah Provinsi Jambi.

\section{DAFTAR PUSTAKA :}

M. Gatto, dkk. 2015. Oil Palm Boom and Land-Use Dynamics in Indonesia : The Role of Policies and Socioeconomics Factors, 292-303

Sri Rahayu, Ade. dkk. 2015. Buku Panduan Konversi POME Menjadi Biogas, USAID dan Winrock Internasional, hlm. 8

BPMD-PPT Provinsi Jambi.2016. Potensi Investasi Provinsi Jambi, hlm. 16

Safrizal.2015. Small Renewable Energy Biogas Limbah Cair (POME) Pabrik Kelapa Sawit Menggunakan Tipe Covered Lagoon Solusi Alternatif Defisit Listrik Provinsi Riau, Jurnal DISPROTEK, 1, 26-35 